\title{
Make Self-help Psychoeducational Programs for Breast Cancer Patients COVID-19 Proof
}

\author{
Jan Passchier ${ }^{1,2,3}$, Hari Setyowibowo ${ }^{1}$, Joke AM Hunfeld ${ }^{3}$, Aulia Iskandarsyah ${ }^{1}$, \\ Whisnu Yudiana ${ }^{1}$, Sawitri S. Sadarjoen ${ }^{1}$, Fransisca D. Badudu ${ }^{4}$, Yusuf Heriady ${ }^{5}$, \\ Drajat R Suardi ${ }^{4}$
}

${ }^{1}$ Faculty of Psychology, Universitas Padjadjaran, Jatinangor, Indonesia. ${ }^{2}$ Faculty of Psychology, Vrije Universiteit Amsterdam, the Netherlands. ${ }^{3}$ Erasmus MC University Medical Center, Rotterdam, the Netherlands. ${ }^{4}$ Hasan Sadikin Hospital, Bandung, Indonesia. ${ }^{5} \mathrm{Al}$ Ihsan Hospital, Baleendah, Indonesia.

\begin{abstract}
The Covid-19 pandemic has significant consequences for the many self-help psychoeducational programs for patients with cancer (symptoms), especially in Low-Middle-Income Countries. We recommend several measures to adapt these programs to the COVID-19 era, such as the use of mobile versions, the addition of preventive measures to be taken by health care providers and patients concerning a hospital visit and the inclusion of psychological advice for coping with COVID-19 related stress. In this way, the double task of preventing the (progression of the) target disease and a contamination by COVID-19 might be optimally fulfilled.
\end{abstract}

Keywords: Cancer- Oncology- Breast- Covid-19- Indonesia- Psychology- Self-help

Asian Pac J Cancer Care, 5 (Suppl 1), 123-125

Submission Date: 07/02/2020Ａcceptance Date: 08/09/2020

\section{Introduction}

The Covid-19 pandemic has significant consequences for the health care all over the world, and among those are the many self-help psychoeducational programs that support cancer patients to cope with their psychosocial problems and to increase adherence to medical procedures.

Psychoeducation refers to therapeutic approaches that involve information giving and receiving, discussion of concerns, problem-solving, coping skills training, expression of emotion, and social support [1]. Psychoeducation has emerged in practice as adjunctive treatments for cancer in which patients and families are struggling with different challenges associated with breast cancer (BC) diagnosis and treatment [2]. Psychoeducation is considered to be less expensive, more easily administered and potentially more accessible than conventional psychological interventions [3].

Most psychoeducational programs for cancer patients focus on coping with the anxiety, depression and stress due to the disease. Information about the disease and the associated health care are often provided as well. Some programs aim at improving the patient's adherence to the medical guidelines. The format of these programs can be face-to-face [4], web-based [5], using a manual [6] or a combination [7].

Our group developed a culture-sensitive self-help psychoeducational program, named PERANTARA, for women with BC symptoms in Indonesia [8]. 'PERANTARA' is an Indonesian acronym which stands for: 'PEngantar peRAwataN kesehaTAn payudaRA, meaning: 'Mediator for the Treatment of Breast Health'. It aims to motivate of women with $\mathrm{BC}$ symptoms to comply with diagnostic procedures and to seek social support. It consists of printed material with information about symptoms and actions to be taken and of audio-visual material with testimonials of two BC survivors. Our recent publication [9], based on data from the pre-COVID-19 period, showed that our program had a significant effect in shortening the time these women took to visit the hospital for diagnosis and treatment. The moment, however, we were planning to implement our program in the local

\footnotetext{
Corresponding Author:

Dr. Jan Passchier

${ }^{1}$ Faculty of Psychology, Universitas Padjadjaran, Jatinangor, Indonesia. ${ }^{2}$ Faculty of Psychology, Vrije Universiteit Amsterdam, the Netherlands.

${ }^{3}$ Erasmus MC University Medical Center, Rotterdam, the Netherlands.

Email: j.passchier@vu.nl
} 
hospitals in Indonesia, the COVID-19 pandemic turned these into potential centres of COVID-19 contamination, because the medical health care, understandably, was not prepared by adequate methods of protection. This situation put many patients with cancer symptoms in a Scylla and Charybdis condition, where a trade-off had to be made between postponing a hospital visit with the risk of a cancer progression, and a hospital visit with the risk of infection by COVID-19. Several patients who are aware of this risk prefer to stay at home because of the fear for contamination. It also made the core message of our PERANTARA program ('visit the hospital as soon as you perceive symptoms that may indicate $\mathrm{BC}$ ') too simple and risky. This situation is, in particular, a problem in Low-Middle -Income Countries (LIMCs), where medical care lacks enough personnel, tools and resources. In Indonesia, for instance, the medical care for cancer patients has been delayed in order to be able to meet the demand for care for COVID-19 patients.

We, therefore, advocate that self-help psychoeducational programs like ours, aiming at reducing patient delays and providing patient support, should be adapted to the new situation. The role of such programs can then even become more important as a tool for helping patients in a situation of lock-down than before.

The publications of the editorial boards of the Indonesian Journal of Cancer [10] and Breast [11] can be considered as a point of departure for the adaptations of self-help programs. These publications provide guidelines, including selection criteria and prioritization of hospital visits, for cancer diagnosis and treatments, according to the pandemic scenario in different countries and /or regions.

When we translate their recommendations into specific adjustments of self-help psychoeducational programs, like our PERANTARA for patients with BC symptoms, we propose in line with their advice the following:

1. Self-help psychoeducational programs should also be provided by mobile phone.

2. Mobile versions of self-help psychoeducational programs should be created that follow the COVID-19 prevention protocols. After recognizing BC symptoms when using such programs, the patient should be able to arrange an online-consultation with a specialized health care professional first (the sooner the better) to estimate the nature and severity of the symptoms, to decide whether a hospital visit is warranted.

3. When this anamnesis indicates that the severity of the symptoms justifies a physical examination and/or treatment at the hospital despite the COVID-19 situation, information must be also provided on the preventive measures taken by the hospital and on those to be taken by the patient against COVID-19

4. The advice to go to hospital for diagnosis or treatment should be tailored to the patient's medical condition and the current health care situation (in particular regarding COVID-19), which may vary by country and region.

5. The programs should include instructions regarding on-line consultation with a specialized health care professional.

6. Instructions to prevent COVID-19 contamination, not only during the hospital visits but also during the journey to and from the hospital, which can also be quite long and risky in LMICs, should be included.

7. It is important to add psychological advice to the self-help programs, which not only focuses on cancer, but also on COVID-19 related fears. Possibilities for referral to more extensive psychological help by telepsychology should be provided as well.

These adaptations imply a number of changes in the medical health care system too. Facilities for on-line contact with medical and psychological interactions need to be developed and sustained. It is crucial, as is also emphasized by Curigliano et al (2020), that such adaptations should be made in a multidisciplinary collaboration of physicians (in particular oncologists), nurses, and psychologists from the country and region involved.

The 'new normal' situation changes rapidly and in a different pace between regions and countries. For example, several hospitals in Indonesia have now separate 'green zones' for patients without COVID-19 symptoms and patients will be checked before entering by temperature screening and questionnaire. It is, therefore, important to monitor the changes in the hospital management of patients with BC symptoms, which are due to the COVID-19 pandemic. The outcome of the monitoring can have implications for the patient's behavior, such as finding the safe way to visit the hospital (how, where and when), and for their coping with COVID-19 related stress. Such implications should lead to corresponding adaptations in the psychoeducational programs. Since these changes may differ between regions in a large country, such monitoring should be done at a regional level as well

The recommendations presented above will be implemented as soon as possible in our PERANTARA program for patients with $\mathrm{BC}$ symptoms in Indonesia. We expect these also to be useful for self-help psychoeducational programs in other patient groups, and in other countries. In this way, the double task of preventing the (progression of the) target disease and a contamination by COVID-19 might be optimally fulfilled.

\section{Funding}

KWF (the Dutch Cancer Society), Grant Number: VU 2012-5572

\section{References}

1. Barsevick AM, Sweeney C, Haney E, Chung E. A Systematic Qualitative Analysis of Psychoeducational Interventions for Depression in Patients With Cancer. Oncology Nursing Forum. 200201 01;29(1):73-87. https://doi.org/10.1188/02. onf. $73-87$

2. Lukens EP, McFarlane W. Psychoeducation as Evidence-Based Practice: Considerations for Practice, Research, and Policy. Brief Treatment and Crisis Intervention. 2004;4:205-25.

3. Donker T, Griffiths KM, Cuijpers P, Christensen H. Psychoeducation for depression, anxiety and psychological distress: a meta-analysis. BMC Medicine. 2009 Dec;7(1). https://doi.org/10.1186/1741-7015-7-79 
4. Chan A, Gan YX, Oh SK, Ng T, Shwe M, Chan R, Ng R, Goh B, Tan YP, Fan G. A culturally adapted survivorship programme for Asian early stage breast cancer patients in Singapore: A randomized, controlled trial. PsychoOncology. 201701 25;26(10):1654-1659. https://doi. org/10.1002/pon.4357

5. Van den Berg SW, Gielissen MFM, Custers JAE, Van der Graaf WTA, Ottevanger PB, Prins JB. BREATH: WebBased Self-Management for Psychological Adjustment After Primary Breast Cancer-Results of a Multicenter Randomized Controlled Trial. Journal of Clinical Oncology. 201509 01;33(25):2763-2771. https://doi.org/10.1200/ jco.2013.54.9386

6. WU P, CHEN S, HUANG W, CHANG S, HSU M. Effects of a Psychoeducational Intervention in Patients With Breast Cancer Undergoing Chemotherapy. Journal of Nursing Research. 2018 08;26(4):266-279. https://doi.org/10.1097/ jnr.0000000000000252

7. Stanton AL, Ganz PA, Kwan L, Meyerowitz BE, Bower JE, Krupnick JL, Rowland JH, Leedham B, Belin TR. Outcomes From the Moving Beyond Cancer Psychoeducational, Randomized, Controlled Trial With Breast Cancer Patients. Journal of Clinical Oncology. 200509 01;23(25):6009-6018. https://doi.org/10.1200/jco.2005.09.101

8. Setyowibowo H, Iskandarsyah A, Sadarjoen SS, Badudu DF, Suardi DR, Passchier J, Hunfeld JAM, Sijbrandij M. A Self-Help Guided Psychoeducational Intervention for Indonesian Women with Breast Cancer Symptoms: Development and Pilot Feasibility Study. Asian Pacific Journal of Cancer Prevention. 201903 01;20(3):711-722. https://doi.org/10.31557/apjcp.2019.20.3.711

9. Setyowibowo H, Hunfeld JAM, Iskandarsyah A, Yudiana W, Passchier J, Sadarjoen SS, Badudu DF, Suardi DR, Hof EV, Sijbrandij M. A self-help intervention for reducing time to diagnosis in Indonesian women with breast cancer symptoms. Psycho-Oncology. 202001 06;29(4):696-702. https://doi.org/10.1002/pon.5316

10. Brahma B. Oncologists and COVID-19 in Indonesia: What can we learn and must do? Indonesian Journal of Cancer. 202003 30;14(1):1. https://doi.org/10.33371/ijoc.v14i1.728

11. Curigliano G, Cardoso MJ, Poortmans P, Gentilini O, Pravettoni G, Mazzocco K, Houssami N, Pagani O, Senkus E, Cardoso F. Recommendations for triage, prioritization and treatment of breast cancer patients during the COVID-19 pandemic. The Breast. 2020 08;52:8-16. https://doi. org/10.1016/j.breast.2020.04.006

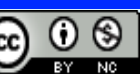

This work is licensed under a Creative Commons AttributionNon Commercial 4.0 International License. 